\title{
Critical Care Nurses' Knowledge Regarding Methicillin-Resistant Staphylococcus Aureus At Mansoura University Child Hospital
}

\author{
Esraa Abd EInasser Ahmed ، INahla Shaban Khalil r Asmaa Ibrahem Abo Seadar \\ 1-Nursing Specialist, Faculty of Nursing, Mansoura University, \\ 2- Professor of Critical Care and Emergency, Nursing Department, Faculty of Nursing \\ - Cairo University, \\ 3-Assist.professor of Critical Care and Emergency Nursing, Faculty of Nursing, \\ Mansoura University.
}

\begin{abstract}
Background: Methicillin Resistant Staphylococcus aureus (MRSA) is a type of bacteria resistant to all $\beta$ lactam antibiotics and it results in formation of small abscess and progress to serious septic endocarditis. The dangers of death in patients with MRSA are three times higher than other infections. Aim of the study: The present study aimed to assess nurses' knowledge related to MRSA at Mansoura University child hospital. Subjects and method: A descriptive exploratory research design was utilized to conduct this study on seventy nurses who are associated with giving direct care for critically ill patients at Mansoura University child hospital in Egypt. Data were collected through using nurses' knowledge assessment questionnaire. Results: Most of nurses obtained unsatisfactory knowledge concerning MRSA (74.3\%.). Moreover, there were significant differences among nurses' knowledge by the demographic characteristics in their knowledge scores regards age, years of working experience, educational level and attends training course. Conclusion: It concluded that nurses had inadequate knowledge about MRSA. Recommendations: Replication of this study on large probability sample, a continuous and effective education should be provided for all nurses to enhance their knowledge about MRSA and Periodic evaluation of nurses' knowledge regarding MRSA.
\end{abstract}

Keywords: Critical care, Nurses' knowledge,Methicillin-Resistant Staphylococcus Aureus. 


\section{Introduction}

There are various kinds of hospital acquired infections; one of the most familiar is induced by a methicillin resistant strain of Staphylococcus aureus (MRSA). MRSA is a kind of staph bacterial infection that is resistant to all present $\beta$-lactam antibiotics, notably, cephalosporins ,carbapenems and penicillins,. The incidence of MRSA is accompanied by significantly worse patients' clinical outcomes. MRSA is responsible for various hospital infections due to its virulence and resistant nature. In some patients, MRSA can be serious and leads to death, and at the least, it can cause painful lesions or sores and a prolonged hospital stay (Lalgudi Ganesan et al., 2020). As well, MRSA infections in neonates can induce many diseases including blood stream infections, brain abscess, pneumonia, meningitis, skin and soft tissue infections, conjunctivitis and bacterial endocarditis, and finally resulting in higher morbidity and mortality (Goldstein et al., 2018).

Nurses may behave as source as well as the vectors for MRSA transmission. Therefore, with inadequate infection control practices among them, the transferring of infection from health care workers to patients can occur more quickly via skin, clothes and instrument contamination. Thus, the awareness regarding the essential roles and the consequences for non-adherence to MRSA transmission prevention practices such as hand washing or hand hygiene. So, wearing gloves and gowns when handling patients are very important to maintain the prevention of MRSA transmission (Seibert et al., 2014;

Jayamaha \& Nagahawatte, 2015).

Because nurses are playing an essential role in transmitting MRSA infections, nurses' knowledge, attitude, and adherence to the safe evidence base guidelines are essential and obligatory to reduce the infection rates. Nurses should be well knowledgeable regarding MRSA routes. As well, they are in a need to know manner of prevention and treatment. Without a knowledgeable nurse, pathogens spread more easily and more patients becoming infected with an MRSA during their hospital stay. On the other hand, increasing nurses' knowledge will enhance the nurses' abilities to prevent the spread of MRSA (Suss, 2017). As well ,the knowledge acquired and perceived by nurses has a great impact on their attitude to repeatedly perform preventive practices to reduce healthcare-associated MRSA (Salem, 2019). Acquiring data regarding nurses' strengths and weaknesses in these categories will focus light on the way the nurses can contribute to the spread of MRSA within clinical settings. Accordingly, areas of weakness can be targeted and fostered education can be delivered to strengthen nurses' infection practices as well as it may assist the hospitals in reducing their MRSA rates.

\section{Significance of the study}

Healthcare-related infections have a greater impact on the morbidity and mortality rates in inside and outside the hospital environment, resulting in an increase in the time spent and costs of hospitalization. The prevention and control of infections are critical for a well-functioning health system (Salem, 2019).

So, provision of care is frequently carried out by nurses and other healthcare personnel in the hospital. Patients who have serious and infectious diseases have the first-hand contact with the nurse. Therefore it is essential to 
ensure that nurses receive the correct knowledge and guidance regarding infection control policy, hand hygiene precautions and antibiotic resistance; as they continuously care for risky patients for multidrug-resistant bacteria (Mamhidir et al., 2010). Furthermore , nurses have a unique position of developing the patient care standards and innovating a change, so they should be aware that nosocomial infections are preventable, have up- to-date information about universal preventions that are accepted globally concerning the prevention and control of infections (Özkal et al., 2014).

\section{Subjects \& Method}

Research design:

A descriptive exploratory research design was utilized to conduct this study. Setting:

This study was conducted in medical and surgical intensive care units. The first ICU provides care for critically ill child patients with multiple medical disorders and the second ICU provides care for critically ill child patients with surgical problems

\section{Sample:}

A convenience sample of seventy nurses working the previous ICUs, available during the data collection, who had at least one year of work experience in the ICU with different educational levels, involved in providing direct care for critical ill child patients and willing to participate in the current study.

\section{Tools of Data Collection:}

Interview questionnaire was used to gather data pertinent to the present study as follow:-This tool was developed by the researcher after reviewing the related recent literatures to assess critical care nurses' knowledge about MRSA. It consisted of two main parts as follows:

\section{Part 1"nurses' demographic data Sheet"}

This part included five items as follows nurses' age, educational level, and years of work experience in ICU and attendance of any previous training program related to MRSA.

\section{Part 2"MRSA \\ knowledge \\ Questionnaire sheet"}

It included 43 questions pertinent to MRSA distributed as follows: knowledge related to general information about MRSA such as definition, causes, complications, colonization, knowledge related to methods of MRSA transmission, knowledge related to MRSA risk factors, knowledge related to clinical signs MRSA, knowledge related to MRSA prevention, knowledge related to MRSA management.

\section{Scoring system:}

One mark was given for the correct answer and zero mark for the incorrect one. The scores obtained for each set of questions were summed up to get the total scores of nurses' knowledge. The total score was computed out of (43).The satisfactory level was considered equal or more than $75 \%$ (equal or more than 32 points), while the score less than $75 \%$ (less than 32 points) was considered unsatisfactory level of knowledge.

Validity and reliability of the tools

Developed tools were tested for content validity by a panel of 5 experts, medical surgical nursing department, critical care nursing department, community nursing department at Faculty of Nursing, Mansoura University, bacteriology department and clinical pathology department Faculty of Medicine at Mansoura University who reviewed the English and Arabic tool for clarity, relevance, and the applicability. 
Modifications were done accordingly. Internal consistency \& reliability of the data collection tools were assessed via Cronbach's Alpha which revealed that $r$ $=0.81$ for knowledge assessment questionnaire.

\section{Pilot study:}

A pilot study was carried out on seven nurses approximately $(10 \%$ of the total sample), to test the clarity, objectivity and applicability of this tool. Accordingly, the seven piloted nurses were excluded from the study and the findings of the pilot study confirmed that the study was feasible.

\section{Ethical Considerations and human rights}

An official permission to execute the study was obtained from the research Ethical Committee and nursing administrator of the hospital after explaining the aim and nature of the study. Then, permission was taken to execute the study. Next, Informed consent form was signed by all the participants after clarifying that participation in this study was voluntary, anonymity and confidentiality were assured through coding of all data, this data will not be reused in another research without their permission and all the information taken about the nurses' knowledge and practices was protected and it doesn't affect their annual appraisal.

\section{Procedure of data collection \\ Phase I: Preparatory phase}

This phase lasted from March to December 2017. It included a review of the recent literature to formulate tools for data collection. The tools were modified by the researcher then translated into Arabic version and tested for validity and reliability. $10 \%$ of the study sample was chosen as a pilot and then excluded from the study.

\section{Phase II: Implementation}

After $t$ obtaining the formal permissions to implement the study, the data collection was initiated since January 2018 to July 2018. The purpose and nature of the study were explained to nurses who agreed to participate. Nurses were asked to fill out the knowledge assessment questionnaire. Data were collected three times per week during the morning, afternoon and night shifts according to involved nurses' time schedule. The researcher was available during nurses' completion of the questionnaire. Each nurse required from 15-20 minute to answer questions.

\section{Statistical design:}

After completion of data collection, data were coded, organized, categorized, computerized and analyzed using the statistical package for social sciences software (SPSS) version 21.Quantitative data were described using numbers and percentages. However, qualitative data were described using median, mean, and standard deviation. Then the interpretation of data was made.

As well, qui square test $\left(\mathrm{X}^{2}\right), \mathrm{p}$ value \& $r$ value were utilized to detect significant correlations. The $\mathrm{p}$ value of $>$ 0.05 demonstrates a significant result while, $p$ value of $>0.05$ demonstrates a non-significant result. As well reliability analysis (Cronbach's Alpha) that is model of internal consistency, based on the average of inter_item correlation. 
Critical Care Nurses' Knowledge Regarding etc...

\section{Results}

Table (1): Frequency distribution of studied subjects according to demographic characteristics $(\mathbf{N}=\mathbf{7 0})$

\begin{tabular}{|c|c|c|}
\hline Variables & $\mathbf{N}$ & $\%$ \\
\hline Age & \multirow{5}{*}{$\begin{array}{l}17 \\
33 \\
17 \\
3\end{array}$} & \\
\hline 25 & & 24.3 \\
\hline $26-29$ & & 47.1 \\
\hline $30-34$ & & 24.3 \\
\hline$\leq 35$ & & 4.3 \\
\hline$\overline{\text { Mean }} \pm$ SD 27.67 \pm 4.14 & & \\
\hline Educational level & & \\
\hline Secondary school diploma & 18 & 25.7 \\
\hline Technical institute of nursing & 22 & 31.4 \\
\hline Bachelor of nursing & 30 & 42.9 \\
\hline Years of work experience & & \\
\hline 4 & 19 & 27.1 \\
\hline $5-8$ & 35 & 50 \\
\hline $9-14$ & 13 & 18.6 \\
\hline$\leq 15$ & 3 & 4.3 \\
\hline$\overline{\text { Mean }} \pm$ SD $6.60 \pm 3.79$ & & \\
\hline Previous attending training course MRSA prevention & & \\
\hline Yes & 10 & 14.3 \\
\hline No & 60 & 85.7 \\
\hline
\end{tabular}

As regard the nurses' age ranged between 20-36 years with mean age 27.67. As well, nearly half of the nurses $47.1 \%$ of them were in the age group from 26 to 29 . While the lowest percentage $4.3 \%$ of them were in the age group $\geq 35$. Regarding educational level, $42.9 \%$ of nurses' were bachelor graduates as well $25.7 \%$ of them were secondary school diploma. experience ranged between 1-16 years with mean 6.60 . Half $(50 \%)$ of the nurses' had 5-8 years and the minority $(4.3 \%)$ of them had $\geq 15$ years of experience. Finally, the majority of the studied subjects $(85.7 \%)$ didn't attend any training program related to MRSA during the working.

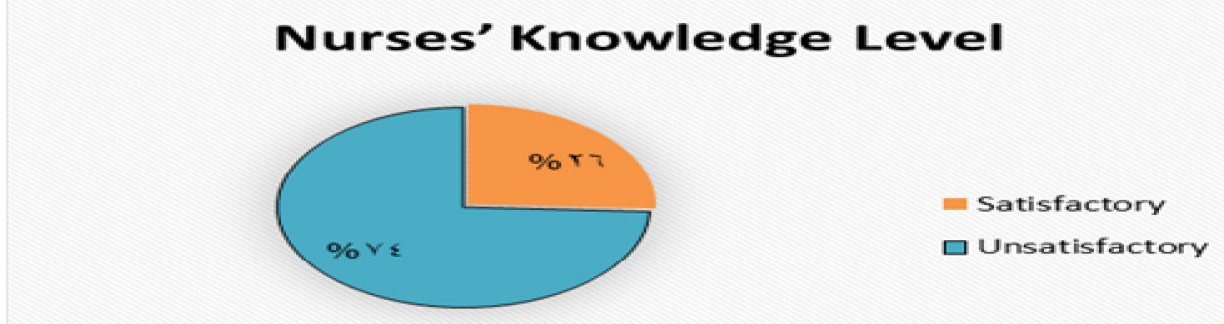 \\ Figure 1: Percentage distribution of the studied subjects as regards to knowledge about MRSA (N. 70) \\ Figure 1 clarifies that the majority $(74.3 \%)$ of the studied subjects had unsatisfactory knowledge level regarding MRSA. \\ Nurses' Knowledge Level}


Esraa Abd Elnasser Ahmed' 'et. al

Table (2): Nurses' knowledge level regarding MRSA (N. 70)

\begin{tabular}{|l|l|l|l|l|l|l|}
\hline \multirow{2}{*}{ Items } & \multicolumn{2}{|l|}{ Unsatisfactory } & \multicolumn{2}{l|}{ Satisfactory } & \multicolumn{2}{l|}{ Chi-square } \\
\cline { 2 - 7 } & $\mathbf{N}$ & $\mathbf{0}$ & $\mathbf{N}$ & $\mathbf{\%}$ & $\mathbf{X}^{\mathbf{2}}$ & P-value \\
\hline General Information & 22 & 31.4 & 48 & 68.6 & 9.657 & $0.002^{* *}$ \\
\hline Transmission & 35 & 50 & 35 & 50 & 0.00 & 1.00 \\
\hline Risk Factors & 55 & 78.6 & 15 & 21.4 & 22.857 & $0.000 * *$ \\
\hline Clinical Signs & 41 & 58.6 & 29 & 41.4 & 2.057 & 0.151 \\
\hline Prevention & 40 & 57.1 & 30 & 42.9 & 1.429 & 0.232 \\
\hline Management & 43 & 61.4 & 27 & 38.6 & 3.657 & 0.056 \\
\hline Total & $\mathbf{5 2}$ & $\mathbf{7 4 . 3}$ & $\mathbf{1 8}$ & $\mathbf{2 5 . 7}$ & $\mathbf{1 6 . 5 1 4}$ & $\mathbf{0 . 0 0 0 * *}$ \\
\hline
\end{tabular}

Table (2): reveals that that majority nurses have unsatisfactory knowledge level regarding risk factors of MRSA $(78.6 \%$,). On the other hand,

have satisfactory level regarding general information $(68.6 \%)$. Moreover, they divided equally regarding transmission more than two thirds of studied nurses of MRSA $(50 \%)$.

Table (3): Mean and standard deviation of MRSA as perceived by the subject group (N. 70)

\begin{tabular}{|ll|l|l|l|l|l|}
\hline Items & Actual score & Mean & SD & Mean Percent & Rank \\
\hline$\bullet$ & General Information & 14 & 10.0714 & 4.29128 & 71.93 & 1 \\
\hline$\bullet$ & Transmission & 4 & 2.4714 & 1.69159 & 61.78 & 3 \\
\hline$\bullet$ & Clinical Signs & 3 & 2.1286 & .84992 & 70.95 & 2 \\
\hline$\bullet$ & Management & 6 & 3.0857 & 2.21158 & 51.42 & 6 \\
\hline$\bullet$ & Precautions & 8 & 4.6143 & 2.48061 & 57.67 & 4 \\
\hline$\bullet$ & Risk Factors & 8 & 4.3857 & 3.08945 & 54.82 & 5 \\
\hline Total & $\mathbf{4 3}$ & $\mathbf{2 6 . 7 5 7 1}$ & $\mathbf{7 . 7 8 5 9 7}$ & $\mathbf{6 2 . 2 3}$ & \\
\hline
\end{tabular}

Table (3): Reveals the mean and standard deviation of MRSA as perceived by the subject group. Generally, it's observed that the overall total mean knowledge score was $26.7571 \pm 7.78597$ with mean percent perceived as the highest knowledge with mean percent $(71.93 \%)$ among the nurses with mean score of $10.0714 \pm 4.29128$. while Management perceived as the lowest knowledge with mean percent 51.42 and mean score $3.0857 \pm 2$

62.23. Specifically, general Information

Table (4): Correlation between nurses' demographic characteristics and their knowledge regarding MRSA (N0.70)

\begin{tabular}{|c|c|c|c|c|c|}
\hline \multirow{2}{*}{ nurses' characteristics } & \multicolumn{3}{|c|}{ Knowledge } & \multicolumn{2}{|c|}{ Test of significance } \\
\hline & \multicolumn{2}{|l|}{ Mean } & SD & $\mathbf{F}$ & P-value \\
\hline \multicolumn{6}{|l|}{ Age group (years) } \\
\hline$>25$ & 22.2353 & & 6.55295 & \multirow{4}{*}{3.026} & \multirow{4}{*}{$.036 *$} \\
\hline $26-29$ & 27.8788 & & 8.57598 & & \\
\hline $30-34$ & 28.1765 & & 6.26733 & & \\
\hline$\geq 35$ & 32.0000 & & 2.00000 & & \\
\hline \multicolumn{6}{|c|}{ Years of working experience } \\
\hline$>4$ & 22.4737 & & 7.13651 & \multirow{4}{*}{3.350} & \multirow{4}{*}{$.024 *$} \\
\hline $5-8$ & 27.6286 & & 8.37744 & & \\
\hline $9-14$ & 29.4615 & & 5.15777 & & \\
\hline$\geq 15$ & 32.0000 & & 2.00000 & & \\
\hline \multicolumn{6}{|l|}{ Educational level } \\
\hline school diploma & 21.7778 & & 6.64703 & \multirow{3}{*}{5.668} & \multirow{3}{*}{$.005 *$} \\
\hline Technical Institute & 28.1364 & & 8.94052 & & \\
\hline Baccalaureate & 28.7333 & & 6.29139 & & \\
\hline \multicolumn{6}{|c|}{ Previous attending training course regarding MRSA prevention } \\
\hline & Number & Mean & SD & $\mathbf{F}$ & P-value \\
\hline No & 60 & 25.6000 & 7.72888 & \multirow{2}{*}{10.562} & \multirow{2}{*}{$.002 *$} \\
\hline Yes & 10 & 33.7000 & 3.26769 & & \\
\hline
\end{tabular}


Table (4) illustrates that there were significant differences among nurses' knowledge by the demographic characteristics in their knowledge scores regards age $(\mathrm{F}=3.026, \mathrm{P}=.036)$, years of working experience $(\mathrm{F}=3.350, \mathrm{P}=$ $.024)$, educational level $(\mathrm{F}=5.668, \mathrm{P}=$ $.005)$ and attends training course $(\mathrm{F}=10.562, \mathrm{P}=.002)$.So, the nurses who their age $\geq 35$ showed higher knowledge. As well, the nurses who had higher experience $\geq 15$ year obtained higher knowledge. Moreover, baccalaureate nurses scored higher knowledge. Finally nurses who attended the MRSA prevention courses showed higher knowledge scores.

\section{Discussion}

In light of the results of the present study, the total numbers of the current studied subjects was $\mathbf{7 0}$ nurses; nearly half of nurses aged between 26 to 29 and were graduated from bachelor of nursing the researcher's point of view might explained as the traditional working styles and job descriptions that necessitate the young nurses to directly deal with patients, and when being older, they would be assigned in managerial duties, Moreover a newly bachelor nursing graduates were appointed in the medical and surgical intensive care units. Differences in educational background from the researcher point of view may be linked to having different types of nursing education in Egypt.

This is similar to the results reported in a previous study conducted by Alwadai (2018) who mentioned that half of the participating nurses ranged from $20<30$ years old. On other hand, these findings are in contrast with Herimat (2016) who carried out a study about Knowledge, Attitudes, and
Adherence MRSA among health care workers and revealed that half of nurses $(49.8 \%)$ was between $26-36$ years old.

In relation to working experience, half $(50 \%)$ of the nurses' had 5-8 years. This finding is not in agreement with that of Suss (2017) who carried out a study about nurse knowledge, attitude, and compliance related to MRSA and revealed that $86.96 \%$ of the studied sample was five years or less years of experience.

The researcher believes that clinical experiences in the emergency departments have a significant effect on the nurses' knowledge which result in improving nurses' compliance with theoptimum performance in all nursing aspects of their field. Clinical experiences are important throughout a nurse's career and make different outcomes.

Concerning nurses' attendance of previous training program related to MRSA, the current findings revealed that large number of nurses had no previous training program related to MRSA. On the contrary, Suss (2017) studywho researched nurse knowledge, attitude, and compliance related to MRSA and found that more than half of nurses had previous training courses regarding MRSA concluded that nearly half of nurses had received meaningful education regarding MRSA.

The researcher believes that this may be due to the scarcity of the nursing staff, with the presence of many work burdens so the number of nurses who went to attend training was few and the training courses play an important role in enhancing and updating nurses' knowledge. So, the nurses should be provided with recurrent training courses 
in the hospital or out of the hospital based on their needs.

The current finding revealed that most of nurses got unsatisfactory level of knowledge regarding MRSA with the mean $(\mathbf{2 6 . 7 5 7 1} \pm \mathbf{7 . 7 8 5 9 7 )}$. The researcher returned back the reasons of inadequate knowledge among nurses to the inadequate supervision of the head nurses, insufficient in-service training in the hospital, absence of rounds and discussion to refresh their knowledge, lack of motivation, increased nurses' workload that affect their motivation to renovate their knowledge.

Moreover, the present finding concerning nurses' knowledge regarding general information, transmission, risk factors, clinical signs, prevention, and management revealed that nearly all nurses revealed unsatisfactory level in knowledge concerning risk factors and control of MRSA. On the other side, the majority of studied nurses have satisfactory level regarding general information. Moreover, they divided equally regarding transmission of MRSA. Our findings is supported by other study conducted by Daniel (2017) who carried out a study about knowledge, attitude and recognized barriers related to the management of patients with MRSA among staff nurses and reported deficiencies in overall knowledge among the studied sample. Similarly, our finding in the current study is in consistent with Jayamaha and Nagahawatte (2015) who conducted a study on knowledge, attitude and practices related to MRSA and revealed that the overall knowledge related to MRSA of most nurses were not satisfactory and there were knowledge gaps in the majority of the nurses.

Concerning the rorrelation
between nurses'

characteristics and their knowledge, the current study revealed that there were significant associations among nurses' knowledge by the demographic characteristics in their knowledge scores concerning age, years of working experience, educational level and attends training courses .So, the nurses who their age $\geq 35$ showed higher knowledge. As well, the nurses who had higher experience $\geq 15$ year obtained higher knowledge. Moreover, baccalaureate nurses scored higher knowledge. Finally nurses who attended the MRSA prevention courses showed higher knowledge scores.

The current positive relationship between age and knowledge may have relevant to the fact that acquiring knowledge increase continuously with increasing age and experience. According to learning theory, the persons learn more by seeing and practicing (Simandan, 2013). Therefore, increasing the years of experience means increasing in knowledge and consequently, begins to practice.

This finding is consistent with Fadeyi (2010) who implemented a study to evaluate awareness, knowledge, and disposition concerning MRSA among nurses in critical care units at a Ngerian hospital and mentioned that nurses' MRSA knowledge was positively correlated with age, work years of experience in critical care units. ,In addition, the previous study done by Daniel (2017), found a positive correlation between staff nurses' years of experience and their level of knowledge. These included nurses' with a higher level of education, nurses' who had more years of professional experience, nurses who had more contact with the infection control nurse and nurses who worked in surgical wards. Consequently, it can be 
concluded that the work years of experience in nursing field correlates positively to greater knowledge score concerning MRSA. Also study conducted by Yassin et al. (2018) and found a positive correlation between staff nurses' years of experience and their level of knowledge.

On the other hand, our finding is not agreed with Shaaban and AbdelFattah (2019); Shaaban and Abdel-Fattah (2019) who implemented a study to investigate the effect educational program pertinent to MRSA prevention and management on the nurses' knowledge and attitude in Egypt and detected no correlations found between nurses' demographic attributes and knowledge concerning management of MRSA.

\section{Conclusion}

Based on the findings of the current study, it can be concluded that the majority of nurses were having an unsatisfactory knowledge regarding MRSA.

\section{Recommendations}

Based on results of the present study the following recommendations were suggested:-

- In service training program must be developed based on nurses' need in relation to infection control.

- Regular appraisal of nurses' knowledge and performance concerning nursing management of MRSA

- Repetition of the study on a larger sample size obtained from different critical care units in Egypt.

- Additional researches needed to recognize the hinders and the effect of nurses' workload on the prevalence of MRSA infection.
References:

Alwadai. (2018). Nursing \& Healthcare. International Journal Knowledge and Practice of Nurses on Healthcare Associated Infection, 2(1), 1-17.

Daniel. (2017). Knowledge, attitude and perceived barriers on care of patients with methicillin-resistant staphyloccocus aureus (mrsa), among staff nurses at a regional hospital, trinidad. International Journal of Advanced Research, 5(4), 1183-1195.

Fadeyi. (2010). Methicilin Resistant $<\mathrm{i}>$ Staphylococcus $\quad$ aureus $</ \mathrm{i}>$ Carriage amongst Healthcare Workers of the Critical Care Units in a Nigerian Hospital. American Journal of Infectious Diseases, 6(1), 18-23.

Goldstein, Jenness, Tuttle, Power, Paul, \& Eppes. (2018). Evaluating a neonatal intensive care unit MRSA surveillance programme using agent-based network modelling. Journal of Hospital Infection, 100(3), 337-343.

Herimat. (2016). Knowledge, Attitudes, and Adherence to Methicillin-Resistant

Staphylococcus aureus Transmission Prevention Among Health Care Workers. (Doctoral dissertatio).

Jayamaha, \& Nagahawatte. (2015). Knowledge, Attitude and Practices Related to MRSA among BSc Nursing Students Who Attend Clinical Training at Teaching Hospital Karapitiya. International Research Conference, 2015(11), 26-30. 
Esraa Abd Elnasser Ahmed' let. al

\begin{tabular}{|c|c|}
\hline $\begin{array}{l}\text { Lalgudi Ganesan, } \begin{array}{c}\text { Mehta, } \\
\text { Lakshmikantha, } \\
\text { Gautam, \& Ray. (2020). }\end{array} \\
\text { Community-Acquired Methicillin- } \\
\text { Resistant Staphylococcus aureus } \\
\text { Infections in Acutely Ill Children: } \\
\text { A Retrospective Case-Control } \\
\text { Study. The Indian Journal of } \\
\text { Pediatrics, 88(2), 141-146. } \\
\text { Mamhidir, Lindberg, Larsson, } \\
\text { Fläckman, \& Engström. (2010). } \\
\text { Deficient knowledge of multidrug- } \\
\text { resistant bacteria and preventive } \\
\text { hygiene measures among primary } \\
\text { healthcare personnel. Journal of } \\
\text { Advanced Nursing, 67(4), 756- } \\
\text { 762. } \\
\text { Özkal, Erem, Özpulat, \& Bas. (2014). } \\
\text { Role of nurses in prevention from } \\
\text { hospital infections. Global Journal } \\
\text { on Advances Pure and Applied } \\
\text { Sciences, 4(4), 171-174. } \\
\text { Salem. (2019). Knowledge and } \\
\text { practices of nurses in infection } \\
\text { prevention and control within a } \\
\text { tertiary care hospital. Annals of } \\
\text { medical and health sciences } \\
\text { research, 9(2), 422-425. }\end{array}$ & 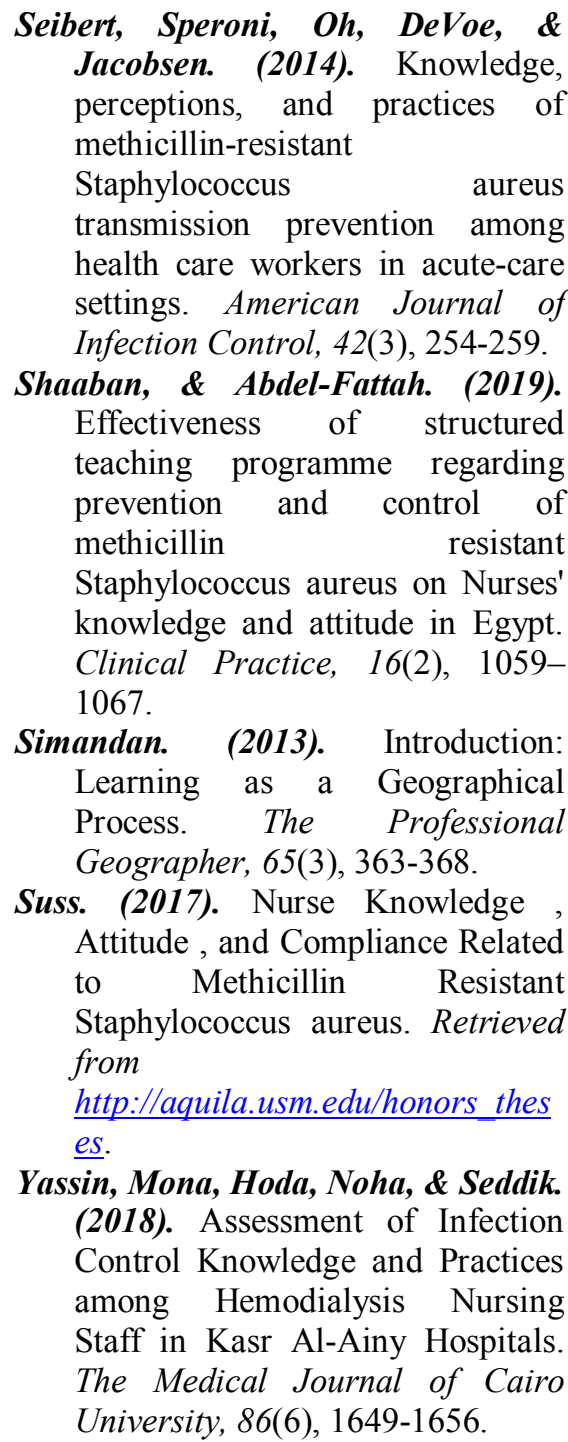 \\
\hline
\end{tabular}

